\title{
When Identifying Contributors is Costly: An Experiment on Public Goods
}

\author{
Anya Savikhin Samek ${ }^{a}$ and Roman M. Sheremeta ${ }^{b}$ \\ ${ }^{\text {a }}$ School of Human Ecology, University of Wisconsin-Madison \\ 1300 Linden Drive, Madison, WI 53706, U.S.A. \\ ${ }^{\mathrm{b}}$ Weatherhead School of Management, Case Western Reserve University \\ 11119 Bellflower Road, Cleveland, OH 44106, U.S.A. \\ and the Economic Science Institute, Chapman University, \\ One University Drive, Orange, CA 92866, U.S.A.
}

February 12, 2014

\begin{abstract}
Studies show that identifying contributors significantly increases contributions to public goods. In practice, however, viewing identifiable information is costly, which may discourage people from accessing such information. To address this question, we design a public goods experiment in which participants can pay a fee to view information about identities and corresponding contributions of their group members. We then compare this to a treatment in which there is no identifiable information, and a treatment in which all contributors are freely identified. Our main findings are that: (1) contributions in the treatment with costly information are as high as those in the treatment with free information, (2) participants choose to view the information about $10 \%$ of the time, and (3) being a high contributor is positively correlated with choosing to view identifiable information about others. Thus, it seems that having access to information is important even when such information is rarely viewed. Our findings have practical implications for non-profit organizations with a large pool of donors and for designers of recognition systems, especially in online communities with many participants.
\end{abstract}

JEL Classifications: C72, C91, H41

Keywords: public-goods, information, experiments

Corresponding author: Anya Savikhin Samek, asamak@ wisc.edu

Financial support was provided through the Network for Computational Nanotechnology, which operated nanoHUB.org with funding by the National Science Foundation under grant numbers EEC-0228390, EEC-0634750, OCI-0438246, and OCI-0721680 and the John Templeton Foundation through the Science of Philanthropy Initiative. We thank Gerhard Klimeck and George Adams III for sharing with us the challenges of online community participation on nanoHUB.org, which gave us the idea to pursue this line of research. We thank Kory Garner for help in conducting experiments. We also thank Jim Andreoni, Timothy Cason, Shakun Datta Mago, Peter DeScioli, Dirk Engelmann, Laura Gee, Justin Krieg, Rob Kurzban, John List, Lise Vesterlund, Stefano DellaVigna, Judd Kessler, participants at the International Economic Science Association meetings, the North America Economic Science Association meetings, and the University of Michigan, University of California-Santa Barbara, and Southern Methodist University for helpful discussions and comments. Any remaining errors are ours. 


\section{Introduction}

It has been generally acknowledged that recognizing contributors by revealing their identities increases contributions to public goods (Andreoni and Petrie, 2004; Rege and Telle, 2004; Karlan and McConnell, 2012; Samek and Sheremeta, 2014). Similarly, recognition has a positive effect on volunteering effort (Linardi and McConnell, 2011), voter turnout (Gerber et al., 2008) and blood donation (Lacetera and Macis, 2010). Benabou and Tirole (2006) propose a model whereby potential donors have social image concerns, and contribute more in settings where they will be recognized. Social groups, charity organizations and online communities publicize individuals' contributions for this reason, and very few contributions are actually done anonymously. However, in practice, there are many environments in which people may choose not to view identifiable information, and contributors may not be aware of whether others view their contributions.

Non-profit organizations with a large pool of donors are a good example. Such organizations often recognize all contributors by publishing lists on websites and in other media, but it is not clear whether freely displaying this information is effective, since people still need to spend time and effort to locate this information (Gabaix et al., 2006). For example, the Krannert School of Management receives over 500 separate donations each year, and publicizes the names of all donors on their website within eight different categories. Interested viewers can click on each category and then peruse this category to determine whether a fellow alumnus has donated 
to the school. ${ }^{1}$ The Purdue School of Pharmacy and Pharmaceutical Sciences has a similar, and even longer list. ${ }^{2}$

Online communities that rely on user contributions may also face similar issues. For example, on the popular question and answer site Yahoo! Answers, a "Leaderboard" announces the total number of answers provided by the contributors of the site, but this information takes time and effort to view. ${ }^{3}$ Similar ranking information is available on the nanoHUB, an innovative research community where users are ordered by amount of voluntarily provided content, and locating the rankings requires several clicks on the webpage. ${ }^{4}$ Empirical studies have noted that users of online websites sometimes ignore information that takes time to find; for instance, on $e B a y$, buyers rarely click through to view detailed feedback information about sellers (Resnick et al., 2006).

We also know little about whether individuals value having access to information about fellow contributors. Eckel and Petrie (2011) find that identifiable information can have a strategic value in a trust game, and that participants are willing to pay for such information. In a related study, Becchetti et al. (2011) find that a large proportion of individuals choose to identify themselves to group members in anticipation of greater utility. List et al. (2004) find that individuals are more likely to vote "yes" to contribute funds to a public project when there is a chance that their vote will be viewed by others. Using a similar approach, Lopez et al. (2012)

\footnotetext{
${ }^{1}$ Information of donors is accessed here: http://www.krannert.purdue.edu/departments/development/report/Report.asp The interested reader may incur the time and effort cost to check whether either of the authors, both alumni of Krannert, have donated to the school last year.

${ }^{2}$ http://www.pharmacy.purdue.edu/advancement/publications/annual_reports/2012/donors.php

3 Yahoo! Answers is one of the top sites on which one can find and share information. The "Leaderboard" can be found at http://answers.yahoo.com/rank_total;_ylt=AvhvsGIO6_Z9A.kmMNpASUrsy6IX;_ylv=3. The "Leaderboard" is only accessible by scrolling down to the bottom of the page, clicking on "About Yahoo! Answers", again scrolling down to the bottom of the page and then clicking on "Leaderboard." Further, gathering information about individual contributors requires scrolling through several pages of information.

${ }^{4}$ The nanoHUB is designed to be a resource to the entire nanotechnology discovery and learning community: http://www.nanohub.org
} 
find that a random public revelation of an individual's contribution is a sufficient motivator to increase public goods contributions. Finally, Kurzban and Descoli (2008) report an experiment in which participants could access information about other participants' contributions to the public good in the previous period. Kurzban and Descoli find that individuals are willing to purchase information on previous-period behavior at a small cost, although imposing the cost decreases aggregate contributions. But despite clear practical applications, it is not clear how individuals value information about identities of fellow contributors and whether such information is helpful in increasing contributions to public goods.

To address this question we, design a public goods experiment in which participants can pay a fee to view information about identities and corresponding contributions of their group members. The fee simulates a time or effort cost generally required to view contributor information in the field. We then compare this to a treatment in which there is no identifiable information, and to a treatment in which all contributors are freely identified. Our main findings are that: (1) contributions in the treatment with costly information are as high as those in the treatment with free information, (2) participants choose to view the information about $10 \%$ of the time, and (3) being a high contributor is positively correlated with choosing to view identifiable information about others. Thus, it seems that having access to information is important even when such information is rarely viewed. Our findings have practical implications for designers of recognition systems, especially in online communities with many participants and for non-profit organizations with a large pool of donors. 


\section{Experimental Environment, Design and Procedures}

While the link between the public goods game in the laboratory and social organizations in the field is imperfect, public goods games have been studied extensively to answer questions about charitable giving and contributions to social communities (Ledyard, 1995; Andreoni and Petrie, 2004; Landry et al., 2006; Chen et al., 2010; Samek and Sheremeta, 2014). In a simple linear public goods game (Groves and Ledyard, 1977), $n$ identical risk-neutral individuals choose a portion of their endowments $e$ to contribute to a public good. Individual $i$ 's contribution $c_{i}$ to the public good is multiplied by $m$ and given to each of $n$ individuals in the group, where $0<m<$ 1 and $m \times n>1$. Thus, each individual $i$ chooses $c_{i}$ to maximize the expected payoff $\pi_{i}=e-(1$ m) $c_{i}+m \sum_{j \neq i} c_{j}$.

We employ the linear public goods game to study how visibility of contributors and cost of identifiable information impact individual contributions. To this end, we conducted three treatments, one in which contributors are anonymous to one another (NONE), one in which all participants are recognized for their contributions (ALL), and a treatment in which all contributors may be recognized, but this information is costly for others to view (COSTLY).

Similar to the designs of Andreoni and Petrie (2004) and Samek and Sheremeta (2014), we chose to use digital photos to identify individuals to one another. ${ }^{5}$ Digital photos capture and preserve the appearance of the person but do not allow for communication, which may confound the effects of identification alone. In addition to the photo, we included first names as part of the identification of individuals. Upon arriving at the lab, each individual wrote his or her first name on a name card, and the experimenter took a photo of the individual holding up the name card.

\footnotetext{
${ }^{5}$ Anonymity is a hallmark of laboratory experiments and making group members known to one another moves us closer to a field setting.
} 
Each individual was then randomly assigned to a computer station in the lab. We used z-Tree (Fischbacher, 2007) to record individual decisions and display photos of individuals.

Individuals were assigned to a group of 5, and stayed in the same group throughout the entire experiment, playing a public goods game for a total of 20 periods. ${ }^{6}$ At the beginning of each period, individuals received an endowment of 80 experimental francs and were asked to choose their level of contribution to the public good. Each individual's contribution to the public good was multiplied by $m=0.4$ and the total of all contributions given to each of the 5 individuals in the group. Each individual kept the remainder of the 80 -franc endowment that he did not allocate to the public good. Individuals did not know others' decisions before making their own decisions. After all individuals made their contributions, the computer displayed the total contribution to the group account and the individual contributions of all 5 group members, sorted by contribution amount from largest to smallest. ${ }^{7}$

In the NONE treatment, no additional identifiable information was revealed, and participants were always anonymous to one another. In the ALL and COSTLY treatments, the photos and names of each group member were displayed on the input screen for all individuals, but we varied the display of identifiable information about contributors on the outcome screen. In ALL, the names and photos of each member were displayed below his or her contribution on the output screen, such that each individual was recognized and also "ranked" (see Figure 1). In COSTLY, after making contribution decisions, and after viewing the default NONE screen with a list of individual contributions but no identification of contributors, individuals had the option

\footnotetext{
${ }^{6}$ Unlike Andreoni and Petrie (2004), we decided to employ a fixed matching design. The main reason for this is that by using fixed matching we amplify the effect of prestige and shame, which we argue are one of the main motivating factors for contributions, and hence create the most conducive environment wherein our conjectures could be tested. Moreover, individuals repeatedly participate in social groups and online communities, and thus we fixed matching design better represents these environments.

${ }^{7}$ While social groups of 5 are rarely observed in practice, the choice of small group allows us to assume that all 5 photos are costlessly viewed by participants when they are displayed by default (e.g., no time cost to view).
} 
to pay a small cost (3 experimental francs; equivalent of $\$ 0.15$ ) to view the identifiable information about all contributors (as in ALL) on the screen. Whether or not their information was viewed by group members was not disclosed to individuals at any time during the experiment.

The experiment was conducted at the Vernon Smith Experimental Economics Laboratory. Participants were recruited from a pool of undergraduate students at Purdue University. A total of 120 individuals participated in 6 sessions, with 20 individuals participating in each session. All individuals participated in only one session of this study. Some individuals had participated in other economics experiments that were unrelated to this research. At the end of the experiment, 2 out of 20 periods were selected for payment using a random draw from a bingo cage. Experimental francs were used throughout the experiment, with a conversion rate of 20 francs $=\$ 1$. Individuals earned $\$ 14$ on average, and sessions (including instruction time) lasted approximately 60 minutes. Individuals also completed a demographic questionnaire at the end of each session.

\section{Experiment Results}

\subsection{Overview}

The standard Nash equilibrium prediction of the public goods game is to contribute nothing (free-ride), i.e. $c^{*}=0$. However, Table 2, which reports summary statistics of our experiment, shows that in all treatments contributions are significantly higher than the standard theoretical benchmark of zero. Figure 2, which reports contributions over all 20 periods, shows that although contributions are declining over time, they are significantly higher than zero in all 
periods of the experiment. ${ }^{8}$ As a result of positive contributions, individuals' payoffs are significantly higher than standard Nash equilibrium predictions. These results are consistent with previous studies of public goods games (Ledyard, 1995; Fehr and Gachter, 2000), suggesting that besides monetary incentives, participants may be driven by social preference concerns, such as pure altruism (Andreoni, 1989, 1990), inequality aversion (Fehr and Schmidt, 1999), fairness and efficiency concerns (Rabin, 1993). ${ }^{9}$

\subsection{Information}

When comparing contributions in NONE to contributions in ALL, we find that, as reported in Samek and Sheremeta (2014), recognizing all contributors significantly increases overall contributions relative to not recognizing contributors (44.2 versus 23.4$).{ }^{10}$ This finding is consistent with previous findings of Andreoni and Petrie (2004), Rege and Telle (2004) and Soetevent (2005). A common explanation for why information about individual identities increases contributions is that the possibility of social recognition introduces prestige and shame as additional motivators for giving (Harbaugh, 1998; Tadelis, 2011). Benabou and Tirole (2006) provide a theoretical model in which individuals have a preference for social image (either social image as a signaling device or social esteem as a consumption good) and contribute greater amounts as the visibility of identifiable information increases. Thurs, our results are consistent both with theoretical considerations and with previous experimental findings.

\footnotetext{
${ }^{8} \mathrm{~A}$ t-test, comparing average contributions to 0 , gives the p-values of less than 0.05 for all treatments.

${ }^{9}$ An additional behavioral motivator that has been cited as important is signaling wealth (Glazer and Konrad, 1996).

${ }^{10} \mathrm{~A}$ Wilcoxon rank-sum test shows that average contributions over all periods in NONE are significantly lower than average contributions over all periods in ALL treatment ( $\mathrm{p}$-value < 0.05 ). The same conclusion holds when looking at periods 6-20 (p-value < 0.05). Note that the data for ALL and NONE comparison treatments comes from the same experimental treatments reported in Samek and Sheremeta (2014).
} 


\subsection{Costly Information}

In the novel COSTLY treatment, we impose a small cost (an equivalent of $\$ 0.15$ per view) on individuals who wish to view the identities of all contributors. A standard utility maximization model would predict that individuals never pay the cost to view identities of other contributors. However, based on previous research showing that information may have a strategic value (Eckel and Petrie, 2011; Becchetti et al., 2011; List et al., 2004; Lopez et al., 2012), we may expect that individuals are willing to pay monetary costs to view identities of other contributors. For example, high contributors may wish to view the information in order to see who was free riding on their contributions. High contributors may also receive utility from being the highest contributors and would like to view their photos in the \#1 or \#2 spot. Conditional cooperators, i.e., individuals who are willing to contribute more to a public good the more others contribute (Fischbacher et al., 2001), may also wish to view this information in order to discern which group members they would like to emulate. Given that information about contributors may be viewed sometimes for the above reasons, we conjecture that contribution levels in COSTLY may be higher than contribution levels in NONE.

Consistent with our conjecture, we find a significant increase in contributions in COSTLY relative to NONE treatment (39.3 versus 23.4). Interestingly, contributions in COSTLY are not significantly different than contributions in ALL (39.3 versus 44.2). ${ }^{11}$ As depicted in the histogram of contributions in Figure 3, the main difference between contributions in COSTLY and ALL versus NONE is that in NONE there is a high frequency of very low contributions, but in COSTLY and ALL the frequency of very low contributions is decreased. This brings us to the first main result:

\footnotetext{
${ }^{11}$ A Wilcoxon rank-sum test shows that average contributions over all periods in COSTLY are not significantly different from average contributions in ALL, but are significantly different from average contributions in NONE ( $p$ values 0.47 and 0.00 , respectively). The same conclusion holds when we use only periods 6-20 (p-value $<0.05$ ).
} 
Result 1: Contributions in the treatment with costly information (COSTLY) are as high as those in the treatment with free information (ALL), and are higher than in the treatment with no identifiable information (NONE).

The fact that contributions in COSTLY are not significantly different from contributions in ALL is unexpected, highlighting the practical importance of making information about identities of all contributions publicly available, even if this information is costly to access. ${ }^{12}$ One reason for this could be that individuals expect others to view contributions at a high rate in COSTLY (recall that, as would be the case in the field, individuals do not receive information about whether their information was viewed). Another reason could be that simply knowing who one is grouped with (as indicated on the input screens in both COSTLY and ALL) is sufficient to increase contribution rates. However, the latter explanation seems less likely given the finding in Samek and Sheremeta (2014) that identifying all contributors on the input screen but only the highest contributors on the output screen is not significantly different from identifying no contributors on either screen.

\subsection{Viewing Behavior}

We now turn to the question: is identifiable information viewed, and when? As previously mentioned, while there is no direct utility from viewing, behavioral and strategic reasons may lead to some viewing. Consistent with this conjecture, we find that participants choose to view the identity of group members $9.25 \%$ of the time. ${ }^{13}$ As displayed in Figure 4, the

\footnotetext{
${ }^{12}$ The increase in contributions in COSTLY may be driven by different factors. First, individuals may believe that group members are viewing their information at a high rate, or close to the rate of views in ALL treatment. Second, simply the chance that one may be recognized is a strong enough motivator to avoid free-riding. These two explanations can be explored in future experiments that control for expectations.

${ }^{13}$ With 20 periods and 40 individuals in the All-Free treatment, the number of times photos are viewed is 74/800 $(9.2 \%)$.
} 
viewing frequency decreases over time, from about $10 \%$ of individuals choosing to view in the first five periods to only $5 \%$ of individuals choosing to view in the last five periods. The modal number of total views per individual across all 20 periods is 1 , with $47.5 \%$ of individuals (38 out of 80) choosing to never view the identifiable information, $23.8 \%$ of individuals (19 out of 80 ) viewing once, and the remaining $28.7 \%$ of individuals viewing 2-10 times. ${ }^{14}$ This brings us to the second result:

Result 2: About half of participants view identifiable information about group members at least once during the experiment; however, over all periods of the experiment participants actually choose to view the information less than $10 \%$ of the time.

As Result 2 confirms, there is evidence that at least half of the participants have some utility from viewing. However, the utility from viewing may be highest in early periods, since there is a higher rate of viewing in early periods relative to later periods. Since participants are grouped with the same individuals over time, and they may expect individuals to act similarly over time, we do not see many participants choosing to view more than 1 time during the experiment.

We now examine who views the photos. It turns out that participants who never choose to view photos contribute on average 33.6 experimental francs in each period, whereas participants who choose to view photos at least once during the experiment contribute on average 43.5 experimental francs in each period. Collapsing data by participant and conducting a Spearman rank correlation test on view rates and contribution levels, we see a positive and significant correlation of 0.32 between viewing and contributing ( $p$-value $=0.04)$. This brings us to the next result:

\footnotetext{
${ }^{14}$ No individual chose to view more than 10 times over the 20 periods.
} 
Result 3: There is a positive and significant correlation between contributing and choosing to view identities of other contributors.

One could imagine the correlation going in either direction - being a high contributor could cause people to view more (in line with a story that high contributors may get more utility from viewing), or viewing more results in higher contributions could cause people to view more (in line with a story that conditional cooperators choose to view, and emulate high contributors after viewing). An analysis of the first period behavior provides some suggestive evidence of the former. In period 1, those who view contribute on average 66.0 to the public good, while those who do not view contribute on average 49.2. However, the result is not statistically significant at conventional levels. Table 3 provides the results of an Arellano-Bond regressions on the effect of past photo viewing and past group contributions on current contribution. As shown in specification (1), the coefficient on view_photo_lag is positive but not significant. However, once we introduce an interaction term between viewing and contributing in specification (2), we find that view_photo_lag is positive and significant (suggesting that in general viewing a photo has a positive effect on contribution) and that view_photo_lag * contribution_lag is negative and significant (suggesting that participants who viewed photos significantly decrease their contributions the higher is their contribution).

\section{Discussion and Conclusion}

The results of our experiment suggest that displaying information about the identities of all contributors, even if this information is costly (i.e., in terms of time and effort needed to discover such information), may be a very effective way to increase contributions to public goods in practice. These results provide practical implications for increasing contributions to 
public goods through changing display of information. Our findings suggest that all identifying information should be displayed, even if it is costly to view, which will lead to greater contributions and a non-negligible amount of viewing of information.

Our findings are relevant for non-profit organizations with a large donor base, such as universities. Alumni giving represents a potential community where universities may wish to publicize all gifts, but the gifts of particular alumni may take time and effort for fellow alumni to view. In this case, our research suggests that despite the visibility challenge, publicizing contributors is still effective. The findings of our experiment also have practical implications for online communities that rely on user-provided content to be successful. While online communities may struggle with how to display contributors when there are hundreds or thousands of them, our research would suggest that as long as this information is public, it is not necessary for it to be readily accessible.

Our finding that contributions and viewing are positively correlated has two implications for theory. First, consistent with a story that individuals care about their social image (Benabou and Tirole, 2006), high contributors may wish to view contributions of others because they either get a utility from seeing themselves as a high contributor, or because they wish to see who the free riders are. This viewing behavior may lead to some decrease in these individuals' contributions in the next period. Second, consistent with a model of Vesterlund (2003), which suggests that recognizable information about donors may lead to greater giving by future donors, a non-negligible number of contributors view information and overall viewing has a positive effect on contributions in the next period. Thus, our results suggest that viewing may lead to higher subsequent contributions and higher contributors may view more. 
Future work should study channels through which costly identification operates. It would be interesting to learn whether it is a high expectation of being viewed, or whether it is the anticipated impact on utility from being viewed that is the primary driving force of increasing contributions. We may also expect behavior to be different if the psychic or monetary cost to view group members' contributions changes. Charging different costs to view different parts of the information would be an interesting extension in this setting, although we expect that the main findings of our paper would still hold. 


\section{References}

Andreoni, J. (1989). Giving with Impure Altruism: Applications to Charity and Ricardian Equivalence. Journal of Political Economy, 97, 1447-1458.

Andreoni, J. (1990). Impure Altruism and Donations to Public Goods: A Theory of Warm-Glow Giving. Economic Journal, 100, 464-477.

Andreoni, J., \& Petrie, R. (2004). Public goods experiments without confidentiality: a glimpse into fund-raising. Journal of Public Economics, 88, 1605-1623.

Becchetti, L., Degli Antoni, G., Faillo, M., \& Mittone, L. (2011). The economic value of a meeting: Evidence from an investment game experiment. Rationality and Society, 23, 403-426.

Benabou, R., \& Tirole, J. (2006). Incentives and prosocial behavior. American Economic Review, 99, 544-555.

Chen, Y., Harper, F.M., Konstan, J., \& Li, S.X. (2010). Social Comparisons and Contributions to Online Communities: A Field Experiment on MovieLens. American Economic Review, 100, 1358-98.

Eckel, C.C., \& Petrie, R. (2011). Face Value. American Economic Review, 101, 1497-1513.

Fehr, E., \& Gachter, S. (2000). Cooperation and Punishment in Public Goods Experiments. American Economic Review, 90, 980-994.

Fischbacher, U. (2007). z-Tree: Zurich toolbox for ready-made economic experiments. Experimental Economics, 10, 171-178.

Fischbacher, U., Gächter, S., \& Fehr, E. (2001). Are people conditionally cooperative? Evidence from a public goods experiment. Economics Letters, 71, 397-404.

Gabaix, X., Laibson, D., Moloche, G., \& Weinberg, S. (2006). Costly information acquisition: Experimental analysis of a boundedly rational model. American Economic Review, 1043-1068.

Gerber, A.S., Green, D.P., \& Larimer, C.W. (2008). Social Pressure and Voter Turnout: Evidence from a Large-Scale Field Experiment. American Political Science Review, 102, 33-48.

Groves, T., \& Ledyard, J. (1977). Optimal Allocation of Public Goods: A Solution to the Free Rider Problem. Econometrica, 45, 783-809.

Harbaugh, W. (1998). The prestige motive for making charitable transfers. American Economic Review, 88, 277-282.

Karlan, D, \& McConnell, M.A. (2012). Hey look at me: The effect of giving circles on giving. No. w17737. National Bureau of Economic Research.

Kurzban, R., \& DeScioli, P. (2008). Reciprocity in groups: information-seeking in a public goods game. European Journal of Social Psychology, 38, 139-158.

Lacetera, N. \& Macis, M. (2010). Social Image Concerns and Prosocial Behavior: Field Evidence from a Nonlinear Incentive Scheme. Journal of Economic Behavior and Organization, 76, 225-237.

Landry, C.E., Lange, A., List, J.A., Price, M.K., \& Rupp, N.G. (2006). Toward an Understanding of the Economics of Charity: Evidence from a Field Experiment. Quarterly Journal of Economics, 121, 747-782.

Ledyard, J. (1995). Public Goods: A Survey of Experimental Research. In J. Kagel and A.E. Roth (Eds.) Handbook of Experimental Economics, Princeton, NJ. 
Linardi, S., \& McConnell, M.A. (2011). No excuses for good behavior: Volunteering and the social environment. Journal of Public Economics, 95, 445-454.

List, J.A., Berrens, R.P., Bohara, A.K., \& Kerkvliet, J. (2004). Examining the role of social isolation on stated preferences. American Economic Review, 94, 741-752.

Lopez, M., Murphy, J., Spraggon, J., \& Stranlund, J. (2012). Comparing the Effectiveness of Regulation and Pro-Social Emotions to Enhance Cooperation: Experimental Evidence from Fishing Communities in Colombia. Economic Inquiry, 50, 131-142.

Rabin, M. (1993). Incorporating Fairness into Game Theory and Economics. American Economic Review, 83, 1281-1302.

Rege, M., \& Telle K., (2004). The impact of social approval and framing on cooperation in public good situations. Journal of Public Economics, 88, 1625-1644.

Resnick, P., Zeckhauser, R., Swanson, J., \& Lockwood, K. (2006). The value of reputation on ebay: A controlled experiment. Experimental Economics, 9, 79-101.

Samek, A. S., \& Sheremeta, R. M. (2014). Recognizing contributors: an experiment on public goods. Experimental Economics, forthcoming.

Soetevent, A. (2005). Anonymity in giving in a natural context- a field experiment in 30 churches. Journal of Public Economics, 89, 2301-2323.

Tadelis, S., (2011). The Power of Shame and the Rationality of Trust. UC Berkeley, Working Paper.

Vesterlund, L. (2003). The informational value of sequential fundraising. Journal of Public Economics, 87, 627-657. 
Table 1: Summary of Treatments

\begin{tabular}{cccc}
\hline \hline Treatment & Display of Identities & $\begin{array}{c}\text { Number of } \\
\text { Individuals }\end{array}$ & $\begin{array}{c}\text { Number of } \\
\text { Independent } \\
\text { Observations }\end{array}$ \\
\hline NONE & No & 40 & 8 \\
ALL & Yes & 40 & 8 \\
COSTLY & Yes if paid to view; No otherwise & 40 & 8 \\
\hline
\end{tabular}

Table 2: Average Statistics

\begin{tabular}{ccccc}
\hline \hline Treatment & $\begin{array}{c}\text { Average } \\
\text { Contribution }\end{array}$ & $\begin{array}{c}\text { Contribution as } \\
\text { \% of Endowment }\end{array}$ & $\begin{array}{c}\% \text { of Contributions } \\
=0\end{array}$ & $\begin{array}{c}\text { \% of Contributions } \\
\text { = Endowment }\end{array}$ \\
\hline NONE & $23.4(0.9)$ & $29.3 \%$ & $34.4 \%$ & $8.3 \%$ \\
ALL & $44.2(1.2)$ & $55.3 \%$ & $22.0 \%$ & $32.8 \%$ \\
COSTLY & $39.3(1.2)$ & $49.1 \%$ & $33.6 \%$ & $32.8 \%$ \\
\hline
\end{tabular}

The standard error of the mean is in parentheses.

Table 3: Arellano-Bond Regressions for COSTLY Treatment

\begin{tabular}{lcc}
\hline \hline & $(1)$ & $(2)$ \\
VARIABLE & Contribution & Contribution \\
\hline contribution_lag & $0.168^{* * *}$ & $0.191^{* * *}$ \\
& $(0.0449)$ & $(0.0470)$ \\
group_contribution_lag & $0.161^{* * *}$ & $0.155^{* * *}$ \\
& $(0.0192)$ & $(0.0193)$ \\
view_photo_lag & 2.822 & $16.48^{* *}$ \\
[=1 if viewed photo in the previous period] & $(3.683)$ & $(7.333)$ \\
view_photo_lag* contribution_lag & & $-0.247^{* *}$ \\
[interaction term] & & $(0.115)$ \\
period & $-0.629^{* * *}$ & $-0.616^{* * *}$ \\
& $(0.186)$ & $(0.187)$ \\
constant & $12.42^{* * *}$ & $12.33^{* *}$ \\
& $(4.816)$ & $(4.837)$ \\
\hline Observations & 720 & 720 \\
Number of participants & 40 & 40 \\
\hline Stand
\end{tabular}

Standard errors in parentheses

$* * * \mathrm{p}<0.01, * * \mathrm{p}<0.05, * \mathrm{p}<0.1$ 


\section{Figure 1: Output Screens for NONE and ALL}

Treatment NONE

\section{Your Group Members}

You are in a group of the same 5 participants each decision period.

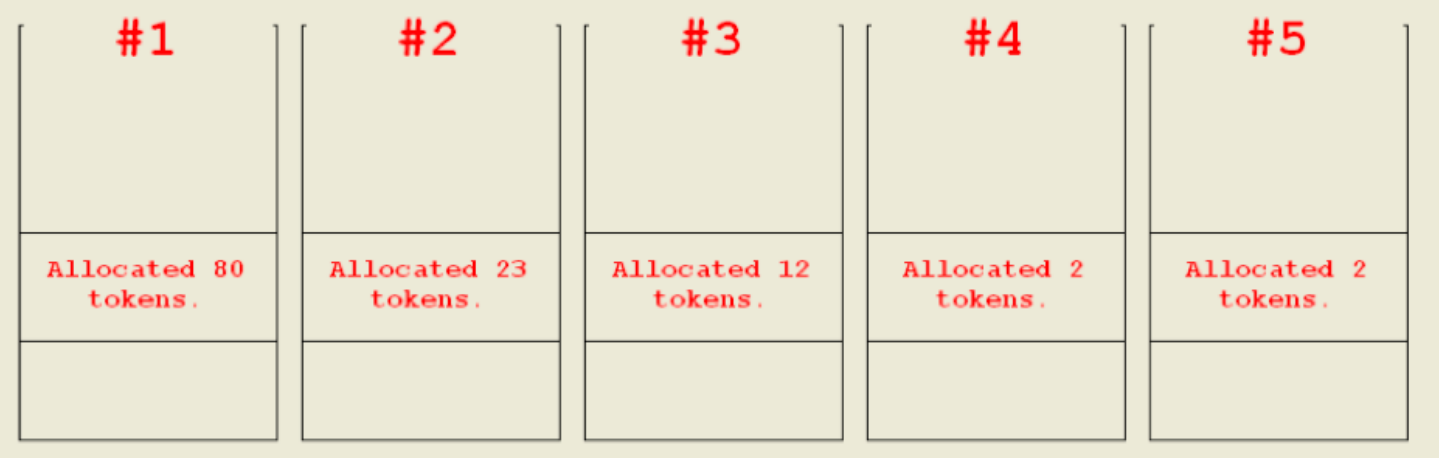

Treatment ALL

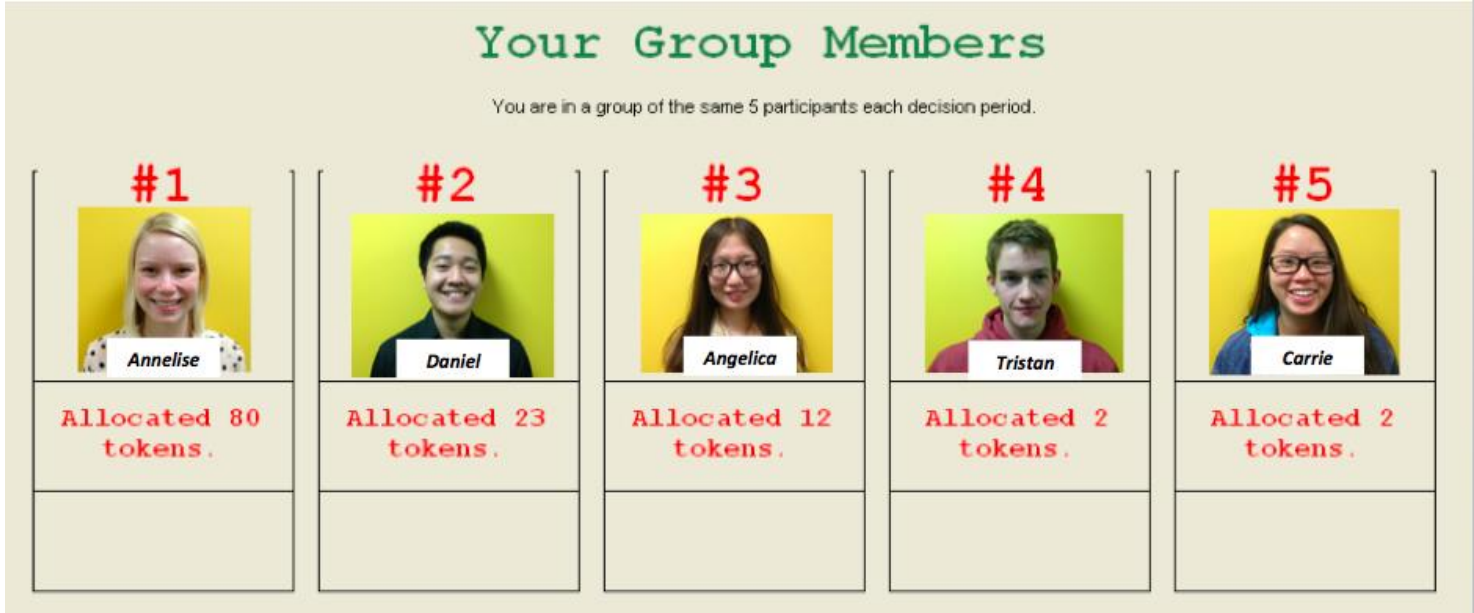

In COSTLY, participants view NONE screen if they choose not to pay for information, and the ALL screen if they choose to pay for information. The numbers above the photo refer to the rank number, not an ID number. Rank number changes in each period based on the ranking of the participant on contribution amount relative to group members. The photos and names depicted in these screens were recreated using undergraduate research assistants in our lab, and are not of actual participants in the study. 
Figure 2: Average Contribution as Percentage of the Endowment over Time
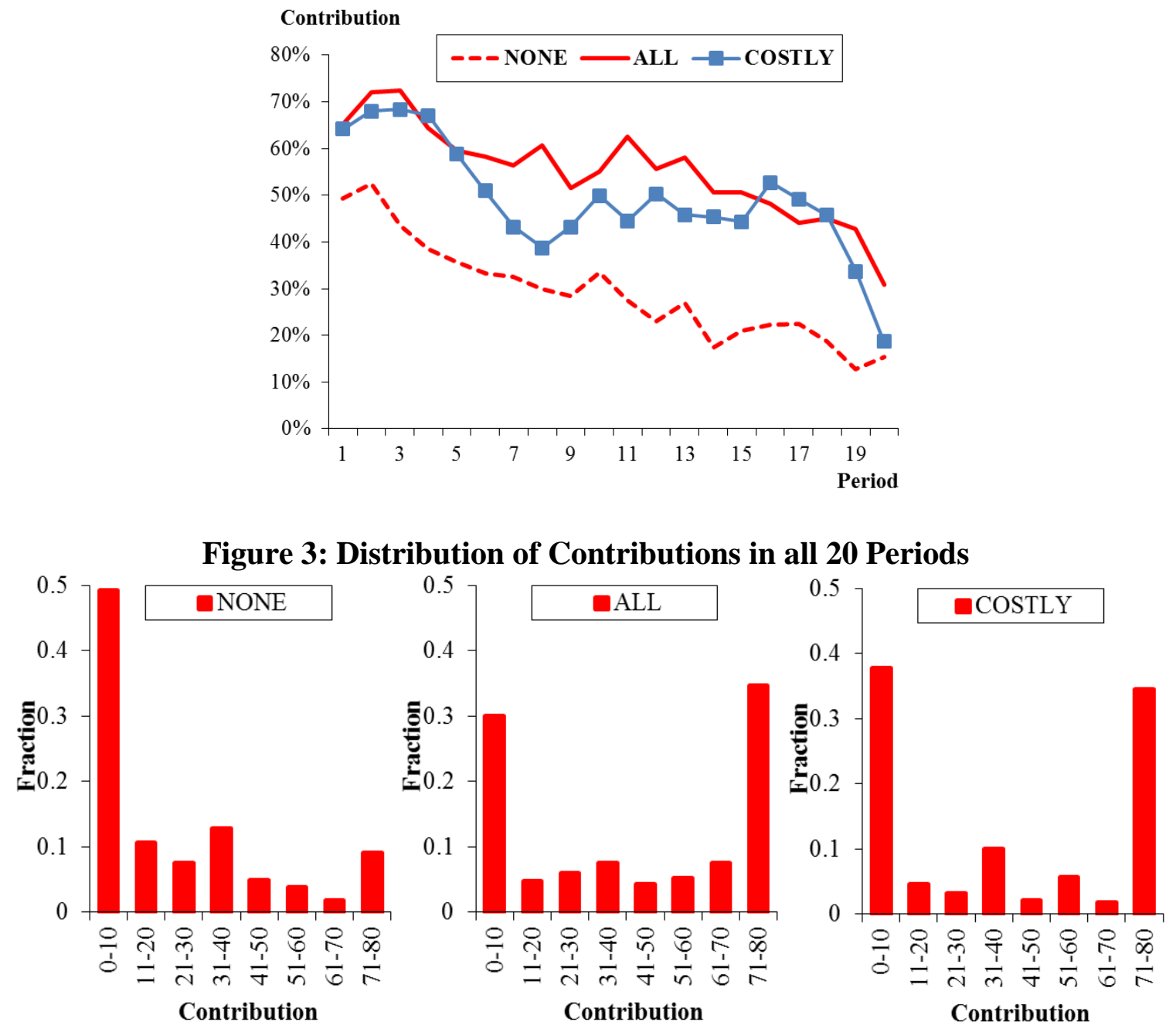

Figure 4: Viewing Photos of Members over Time in COSTLY Treatment

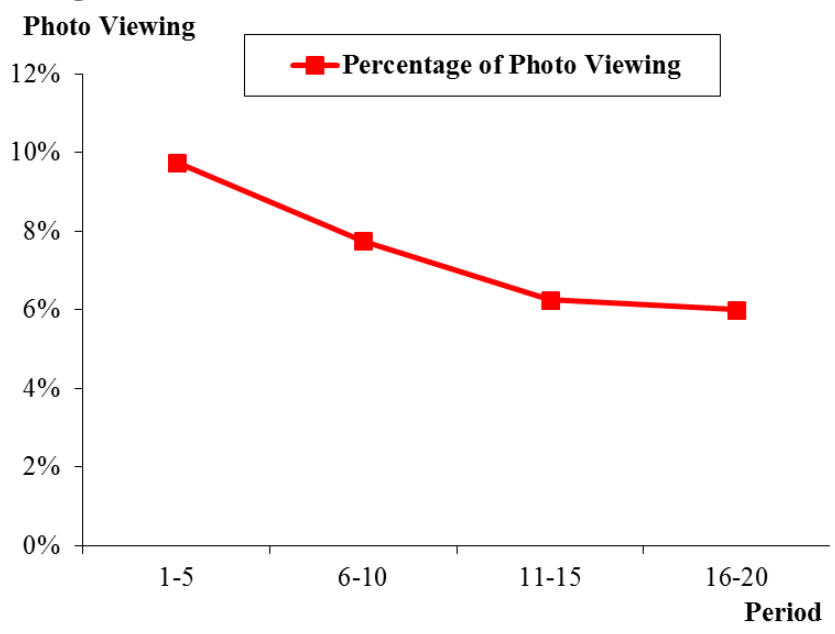




\section{Appendix (For Online Publication): Instructions for COSTLY Treatment}

\section{INSTRUCTIONS}

In this experiment you will be placed in a group of $\mathbf{5}$ participants (including you). You will remain in the same group for the entire experiment. The experiment will consist of 20 periods. At the end of the experiment 2 out of 20 periods will be randomly selected for payment. After you have completed all periods two tokens will be randomly drawn out of a bingo cage containing tokens numbered from 1 to $\mathbf{2 0}$. The token numbers determine which two periods are going to be paid in the game.

Each period you will be given $\mathbf{8 0}$ francs. Francs will be converted to U.S. dollars at the end of the experiment at the rate of $\mathbf{2 0}$ francs $=\mathbf{\$ 1}$. Each period you will be asked to decide how many francs you want to allocate to a Group Account. You may allocate any integer number of francs between $\mathbf{0}$ and $\mathbf{8 0}$. The remainder will be automatically allocated to your Individual Account.

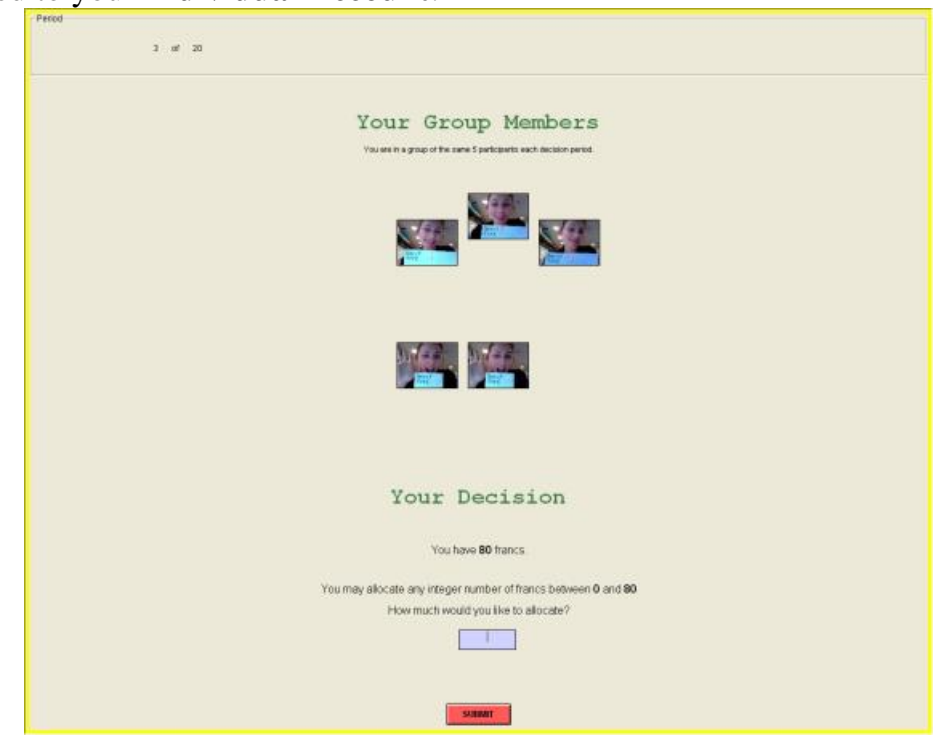

\section{EARNINGS}

After all participants have made their decisions, your earnings for the period are calculated. These earnings will be converted to cash and paid at the end of the experiment if the current period is the period that is randomly chosen for payment. Your earnings consist of two parts:

1) Your earnings from the Individual Account

2) Your earnings from the Group Account

Your earnings from the Individual Account equal to the francs that you keep for yourself and do not depend on the decisions of others. Therefore, for every franc you keep for yourself in your Individual Account, you earn 1 franc.

Your earnings from the Group Account depend on the total number of francs allocated to the Group Account by all 5 group members (including you). In particular, your earnings from the Group Account are 40 percent of the total allocation of all 5 group members (including you) to the Group Account. Therefore, for every franc you allocate to the Group Account, you increase the total allocation to the Group Account by 1 franc. Therefore, your earnings from the Group Account rise by $0.4 \times 1=0.4$ francs. And the earnings of the other group members also rise by 0.4 francs each, so that the total earnings of the group from the Group Account rise by 2.4 francs.

In summary, your period earnings are determined as follows:

Your earnings $=$ earnings from the Individual Account + earnings from the Group Account $=$

$=80-($ your allocation to the Group Account $)+0.4 \times$ (allocation of 5 group members to the Group Account)

Example: Suppose that you allocated 40 francs to the Group Account and that the other four members of your group allocated a total of 120 francs. This makes a total of 160 francs in the Group Account. In this case each member of the group receives earnings from the Group Account of $0.4 \times 160=64$ francs. In addition, you also receive 40 francs from your Individual Account since you have kept 40 francs to your Individual Account. 


\section{OUTCOME SCREEN}

At the end of each period, your allocation and the sum of all allocations in your group are reported on the outcome screen as shown below. To aid you in your calculation, you are also shown your earnings from your individual account and your earnings from the group account. Once the outcome screen is displayed you should record your results for the period on your Personal Record Sheet under the appropriate heading.

The photos and names of each member of your group will be displayed on the top of your screen at all times. At the end of each period, the photos of all group members will be re-arranged by the number of francs allocated to the Group Account in that period.

The allocations will be ranked from highest allocation to lowest allocation, and the amount of each group member's allocation will be listed on the screen.

\section{RANKING}

Further, each member in the group will be given a ranking, corresponding to the number of tokens allocated in that period within the group. For example, the member with the highest allocation in the group will be given the ranking of \#1, the group member with the second-highest allocation will be given the ranking of \#2, and so on. You have the choice to see the ranking of each group member as well as your own ranking. If you choose to view the rankings, click on "yes" for the question "Would you like to view the rankings?" If you choose to view the rankings, you will pay 3 experimental dollars, which will be subtracted from your outcome in each period, and the photo and name of each group member will be listed below his or her ranking on the screen. If you choose not to view the rankings, click on "no" for the question "Would you like to view the rankings?" If you do not view the rankings, you will not pay 3 experimental dollars.

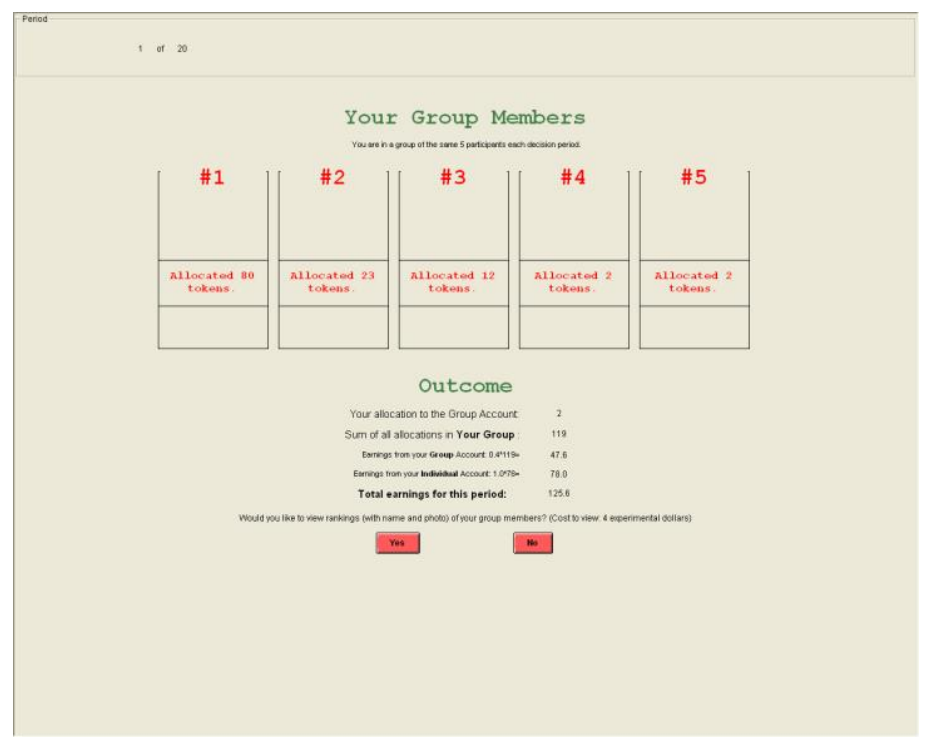

